Submitted to JACS

\title{
The mechanistically significant coordination chemistry of dinitrogen at FeMo-co, the catalytic site of nitrogenase.
}

Ian Dance

School of Chemistry, University of New South Wales, Sydney, 2052, Australia.

I.Dance@unsw.edu.au

\section{Supplementary material}

Fig S1. The complete set of calculated structures and reaction profiles for $\eta^{2}-\mathrm{N}_{2}$ coordinated at hydrogenated FeMo-co.

Fig S2. The complete set of calculated structures and reaction profiles for $\eta^{1}-\mathrm{N}_{2}$ coordinated at the endo position of $\mathrm{Fe} 6$ or $\mathrm{Fe} 2$ in hydrogenated FeMo-co.

Fig S3. The complete set of calculated structures and reaction profiles for $\eta^{1}-\mathrm{N}_{2}$ coordinated at the exo position of $\mathrm{Fe} 6$ or $\mathrm{Fe} 2$ in hydrogenated FeMo-co. 

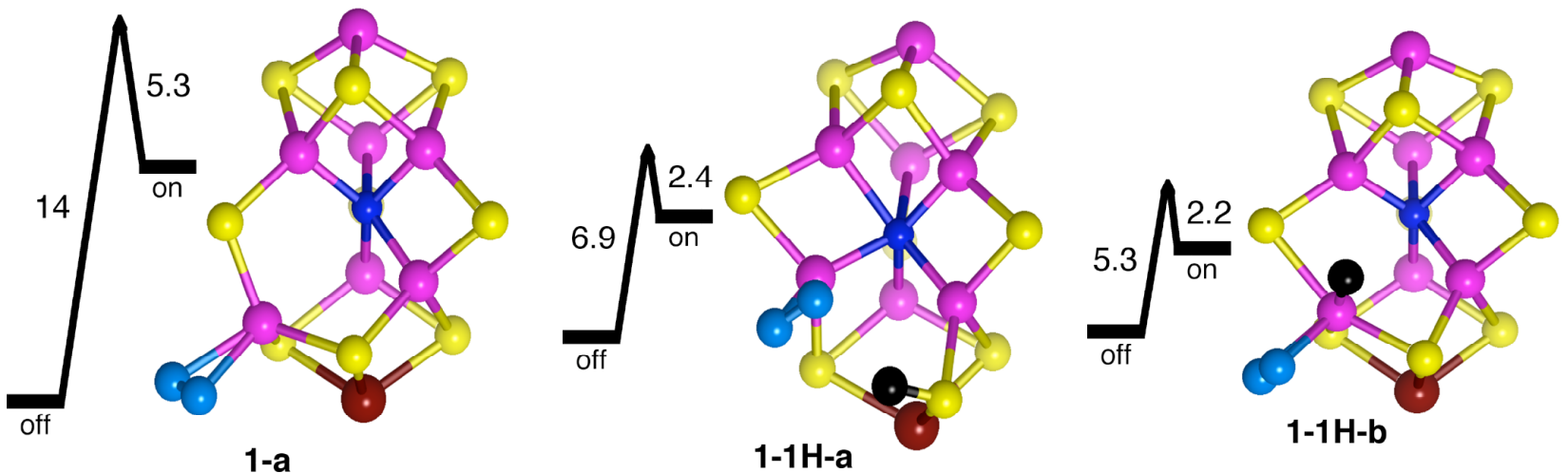

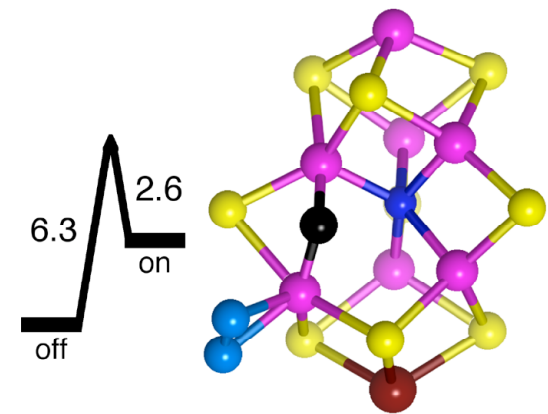

1-1H-c

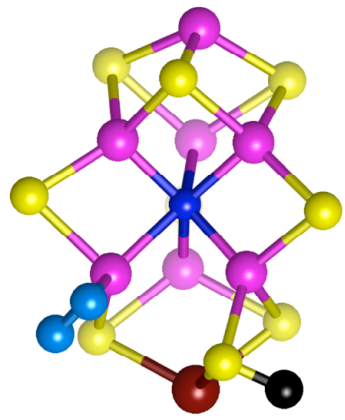

1-1H-f

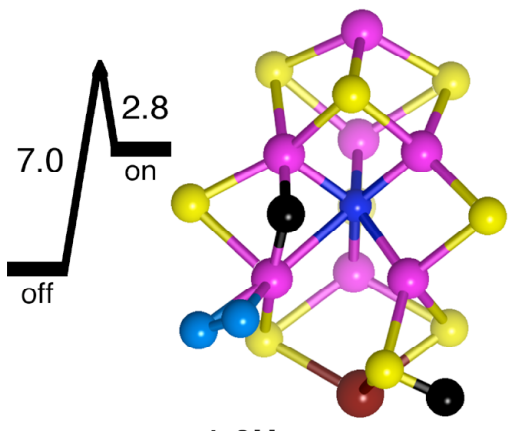

1-2H-a

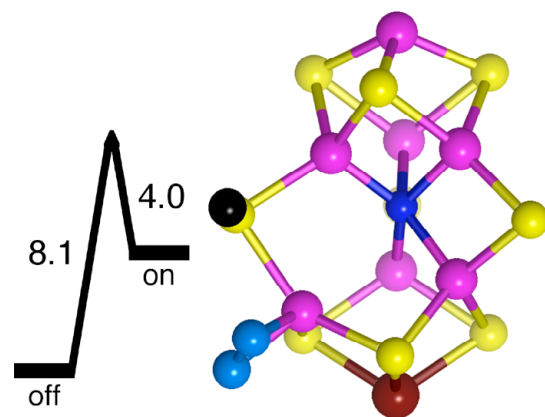

1-1H-d

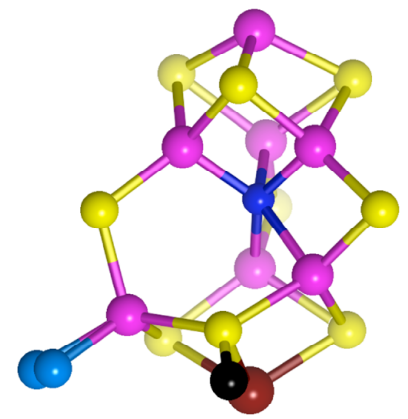

1-1H-g

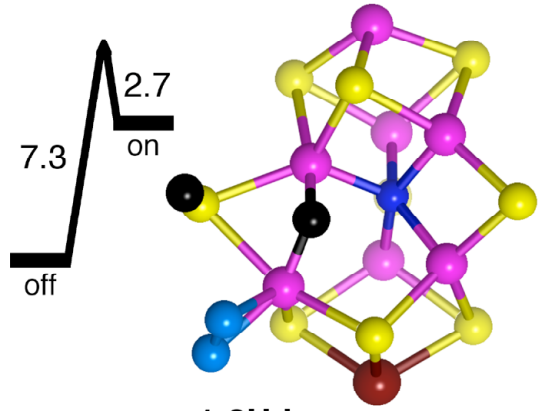

1-2H-b
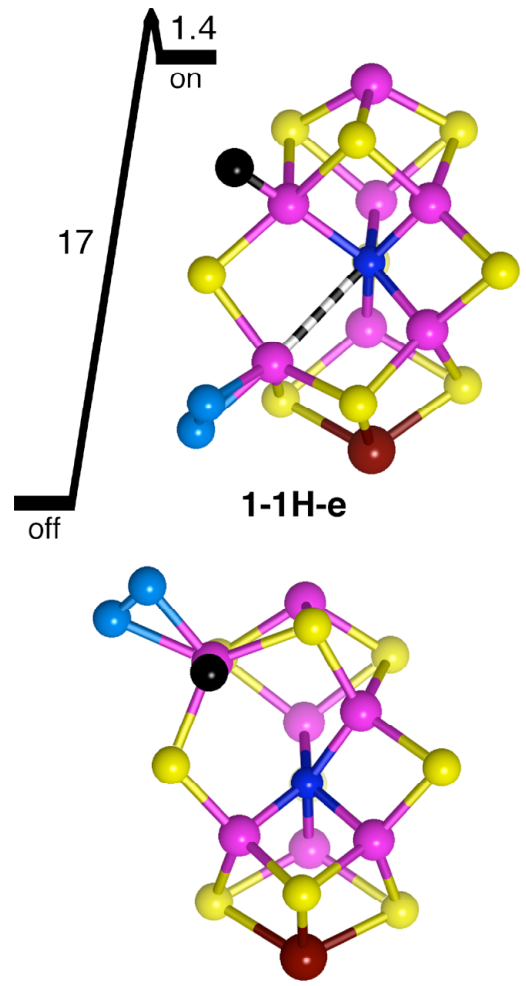

1-1H-h

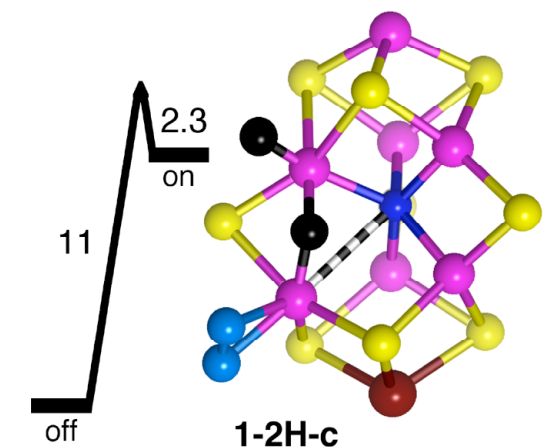




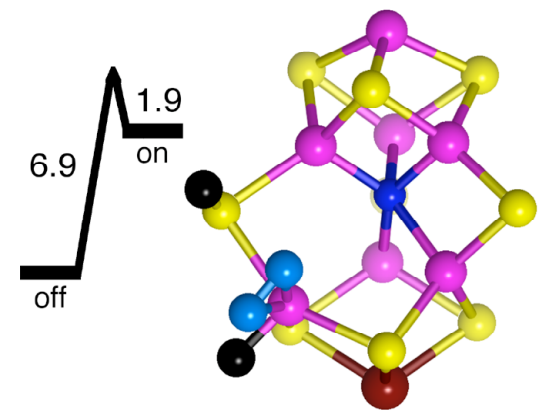

1-2H-d
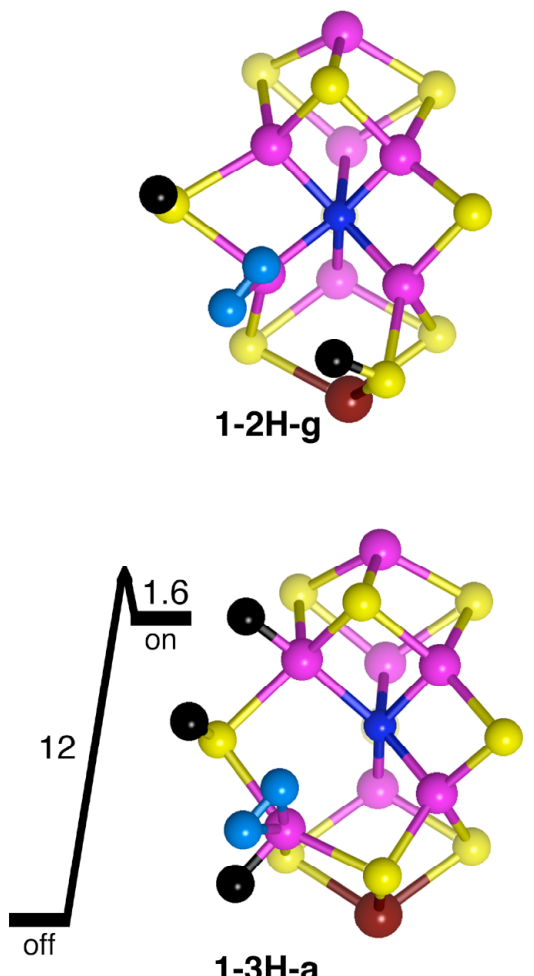

1-3H-a

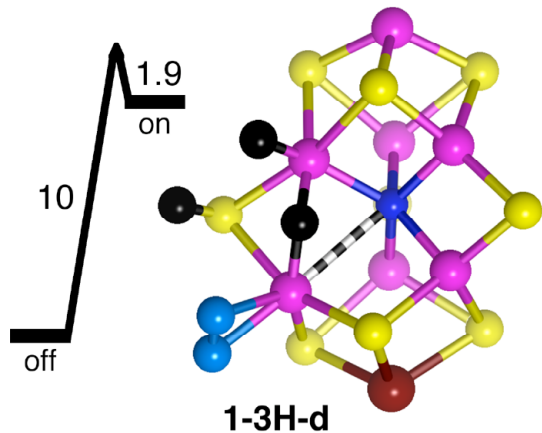

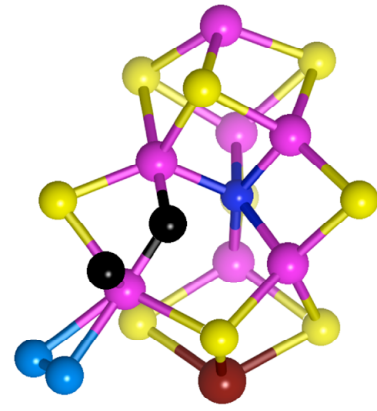

1-2H-e
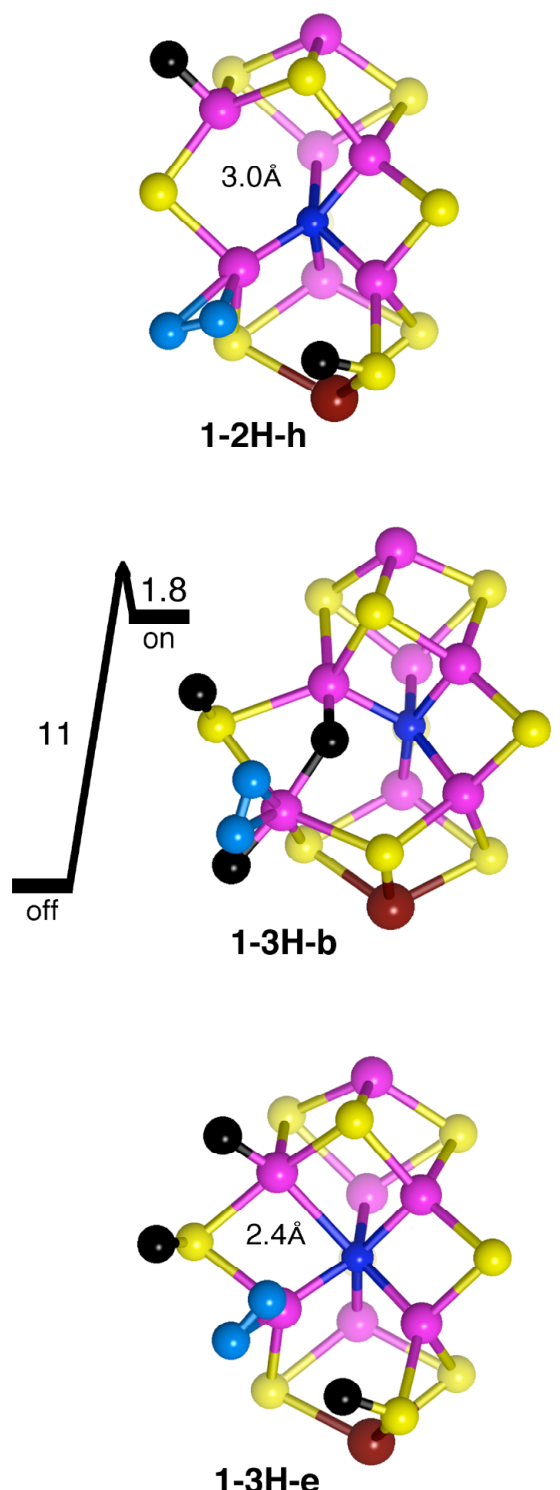
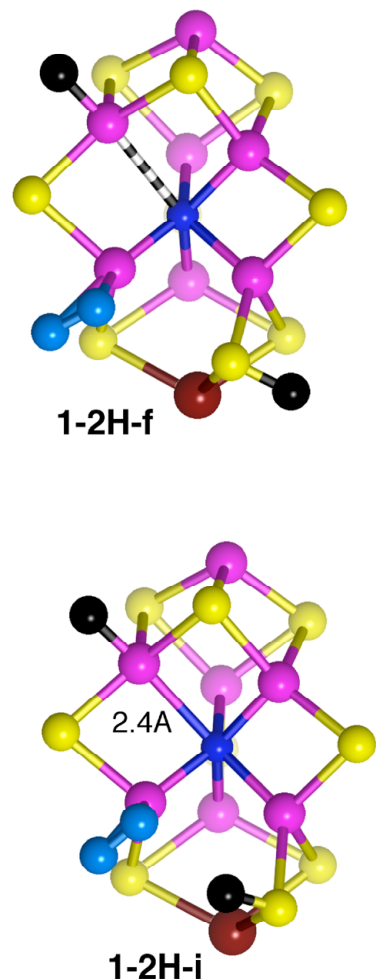

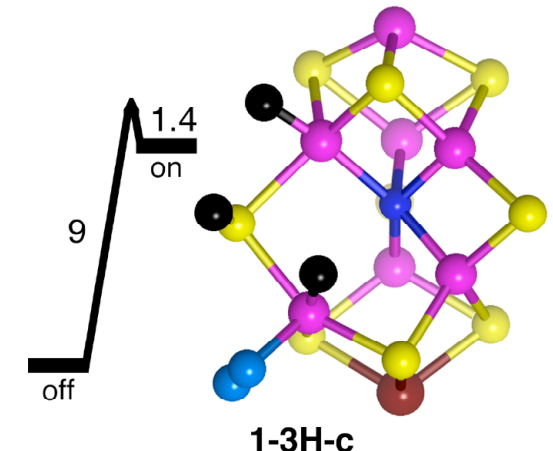

1-3H-c

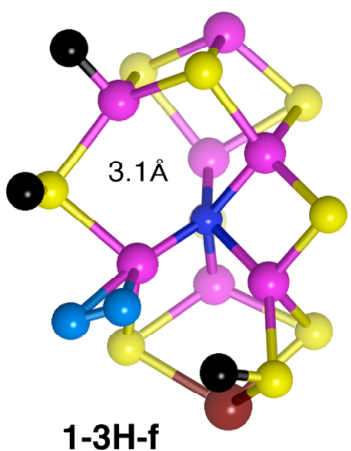



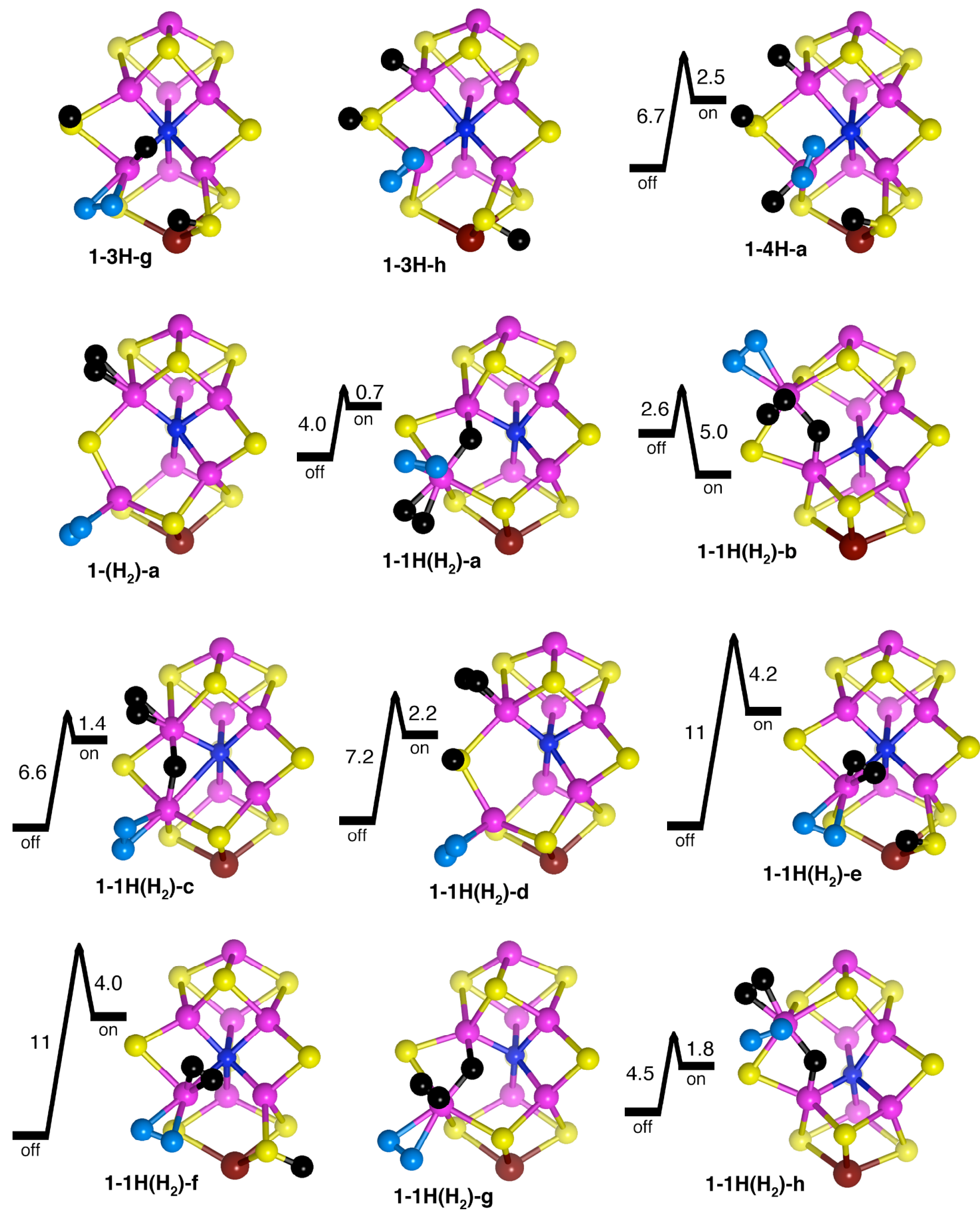

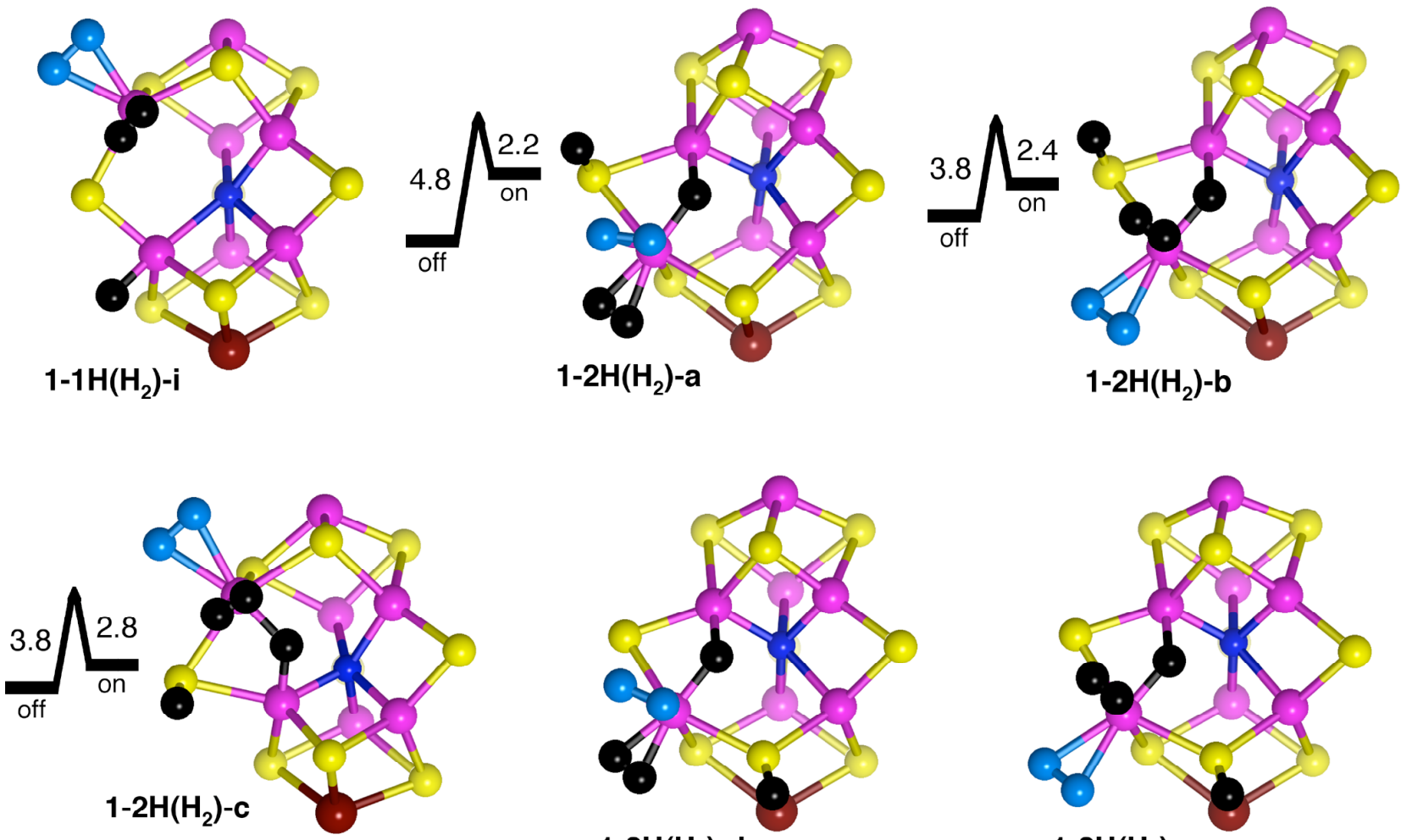

$1-2 H\left(H_{2}\right)-d$
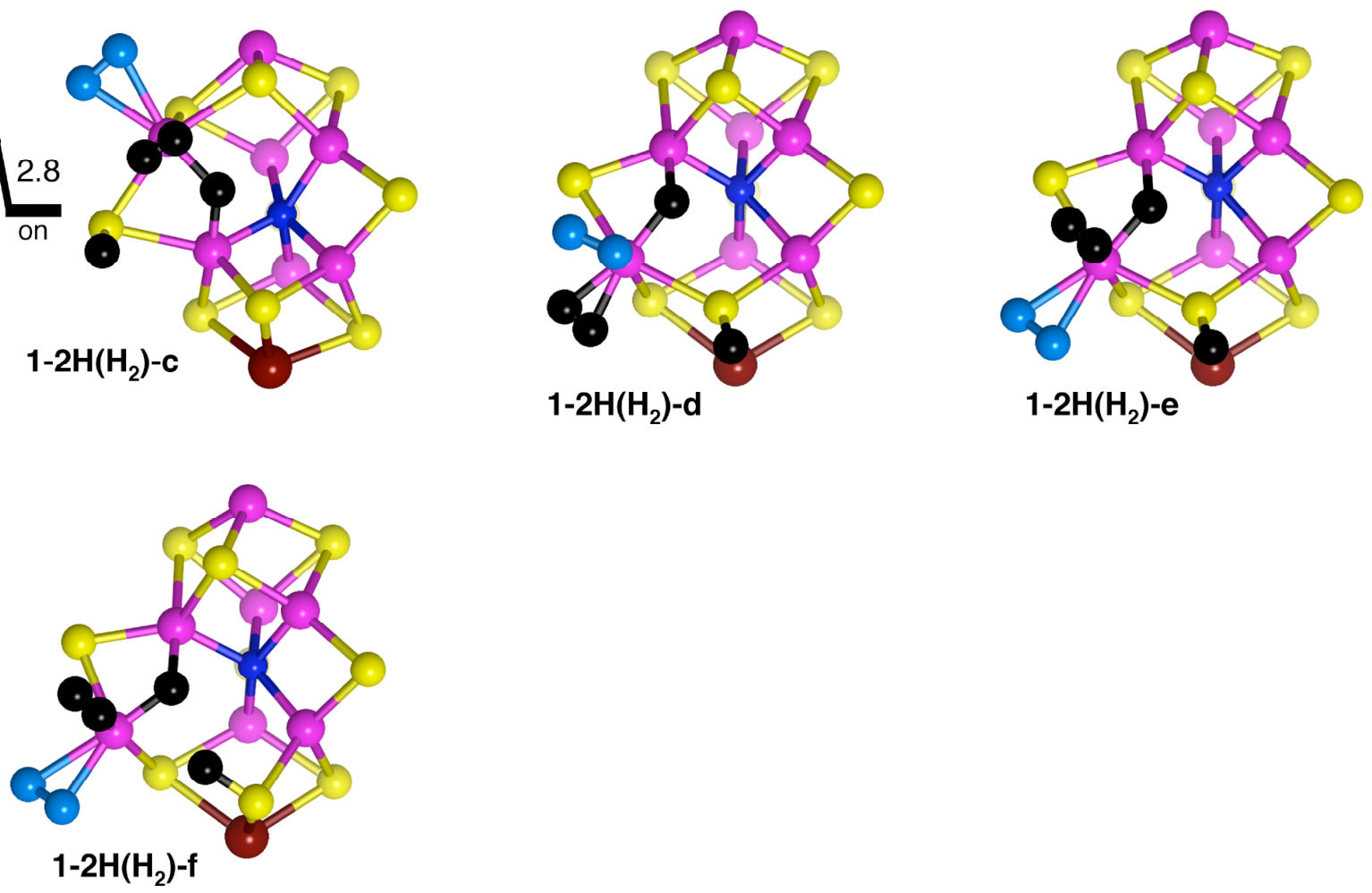

Fig S1. The complete set of calculated structures and reaction profiles for $\eta^{2}-\mathrm{N}_{2}$ coordinated at hydrogenated FeMo-co. 


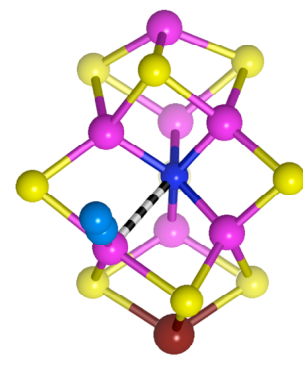

2-a
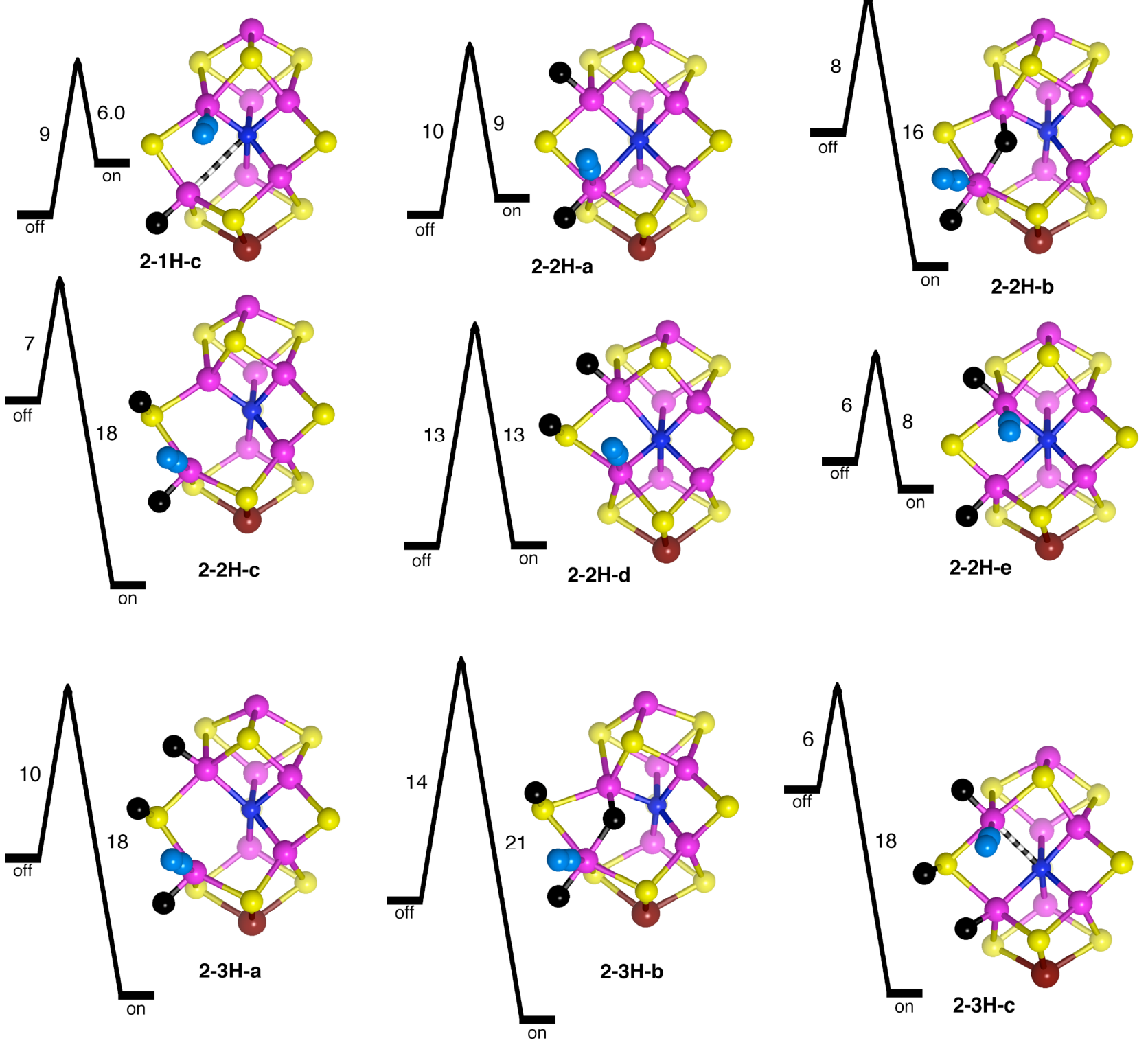

2-2H-e
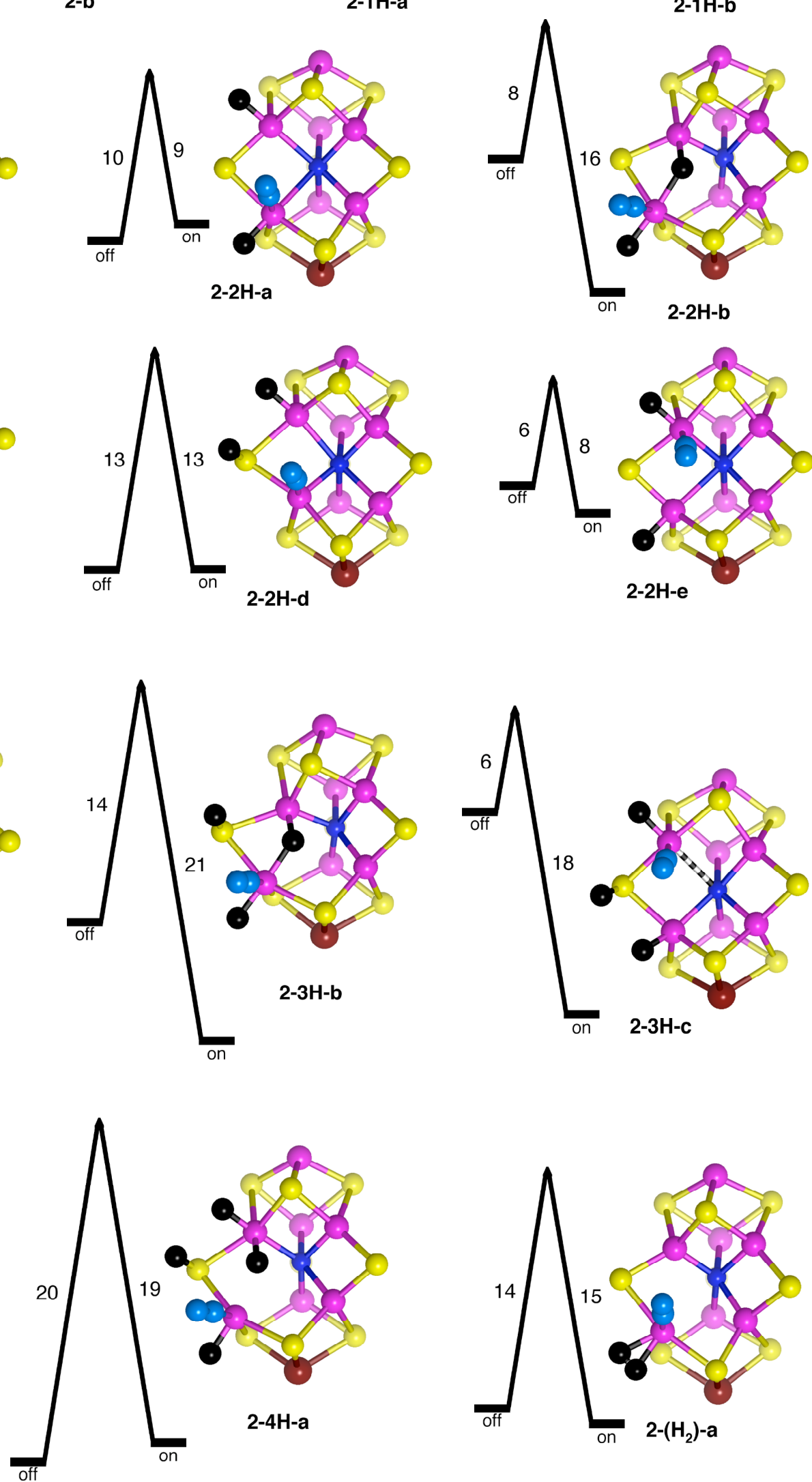

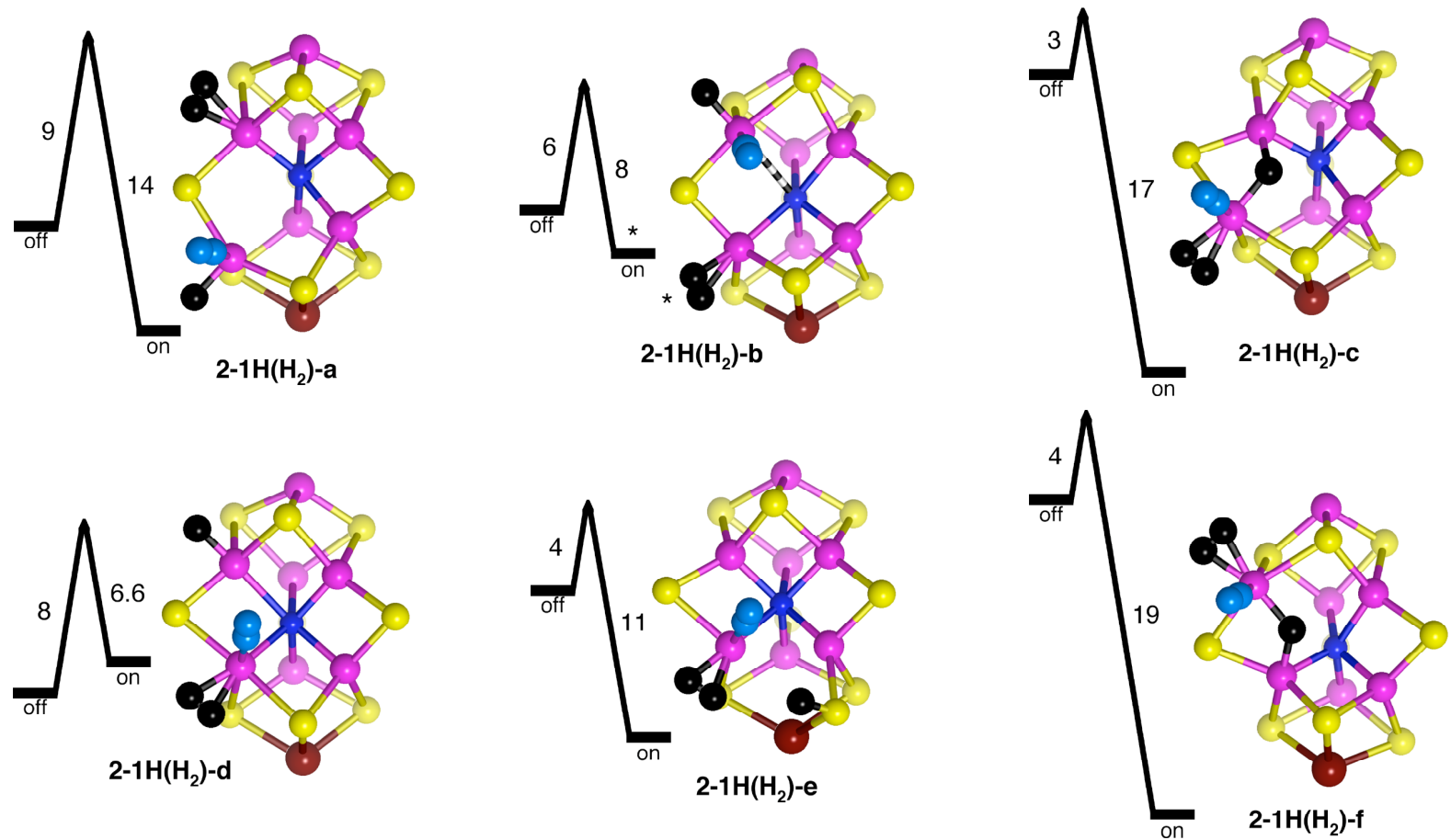

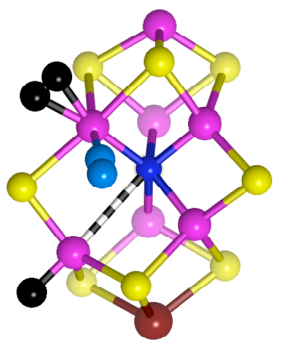

2-1H( $\left.\mathbf{H}_{2}\right)-g$

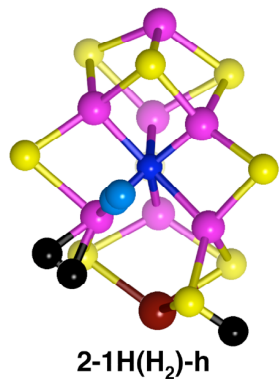

2-1 $\mathrm{H}\left(\mathrm{H}_{2}\right)-\mathrm{h}$
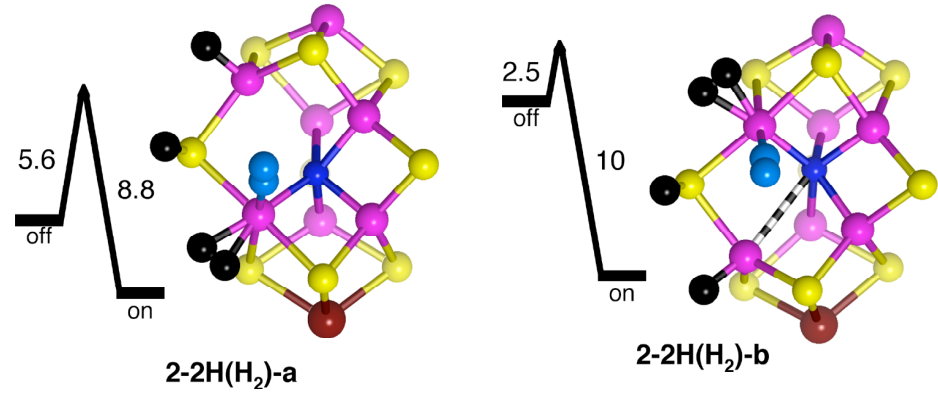

Fig S2. The complete set of calculated structures and reaction profiles for $\eta^{1}-\mathrm{N}_{2}$ coordinated at the endo position of $\mathrm{Fe} 6$ or $\mathrm{Fe} 2$ in hydrogenated FeMo-co. * The associated state is unstable to dissociation of $\mathrm{H}_{2}$, as described in the text. 


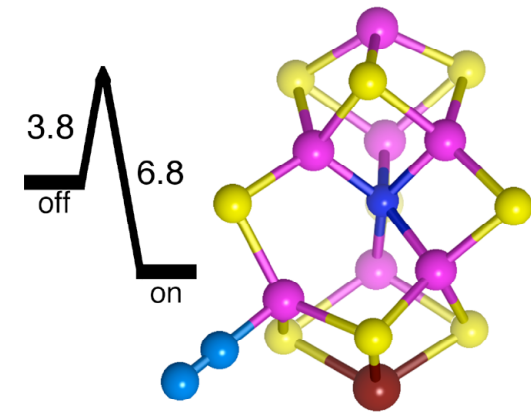

3-a
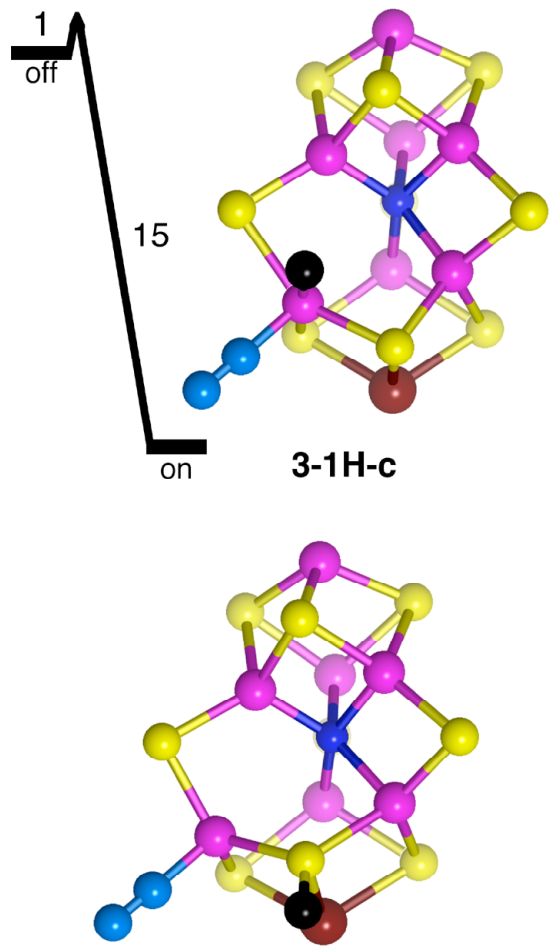

3-1H-f

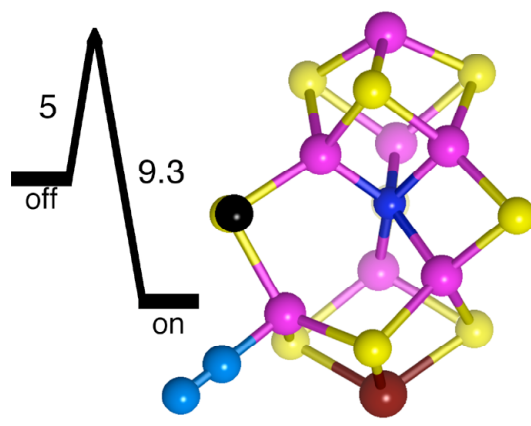

3-1H-a

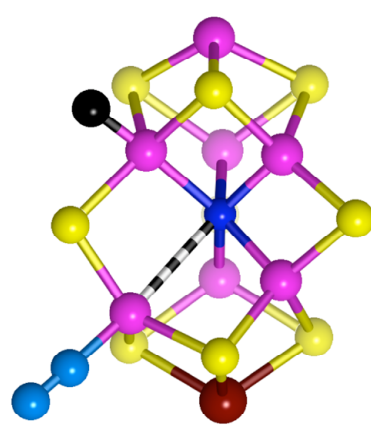

3-1H-d

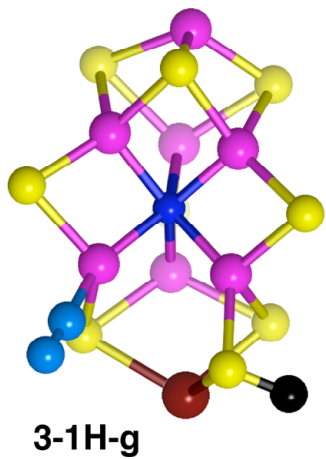

3-1H-g

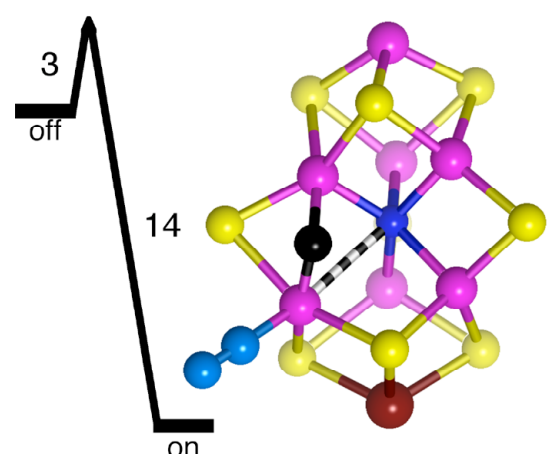

3-1H-b

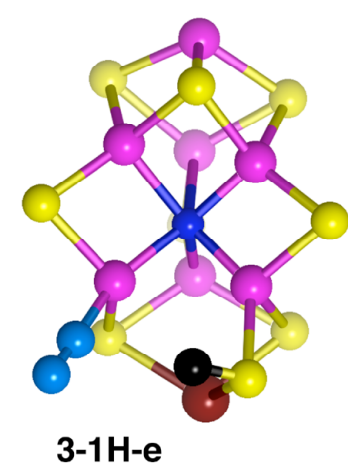

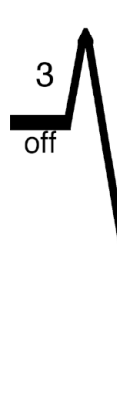

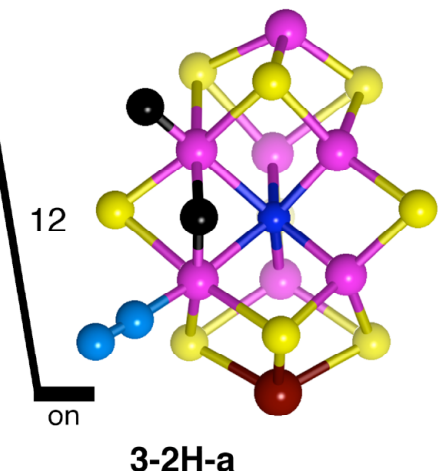

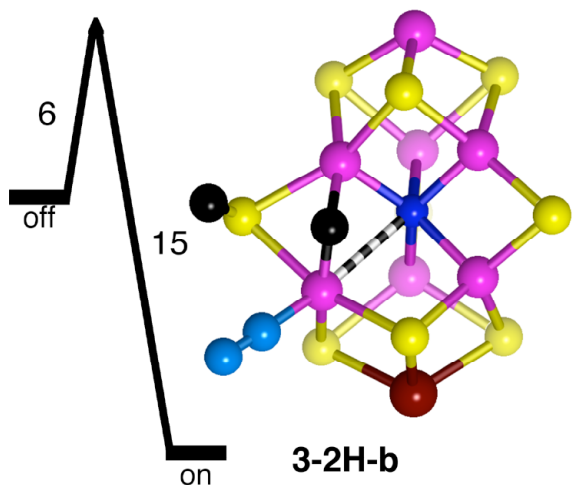
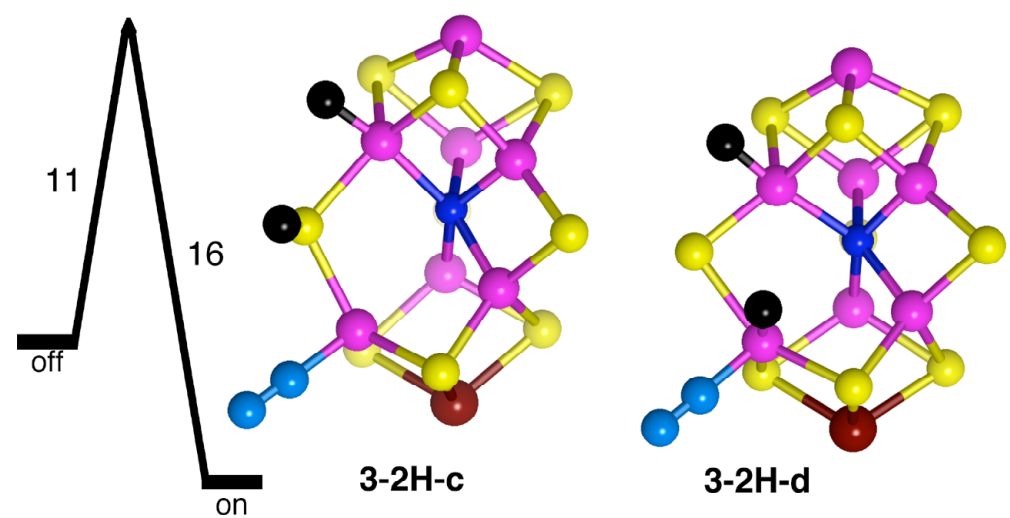

3-2H-d 


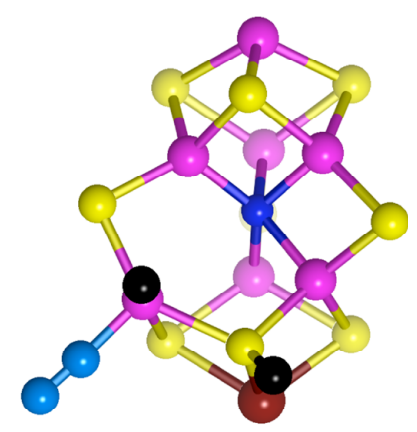

3-2H-e

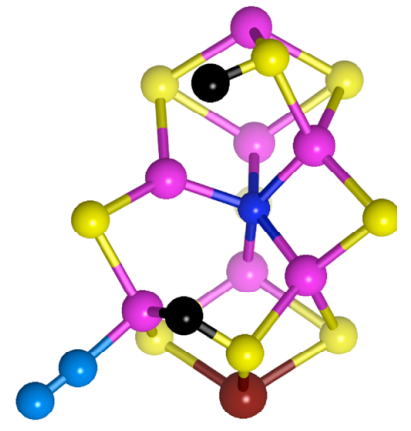

3-2H-f

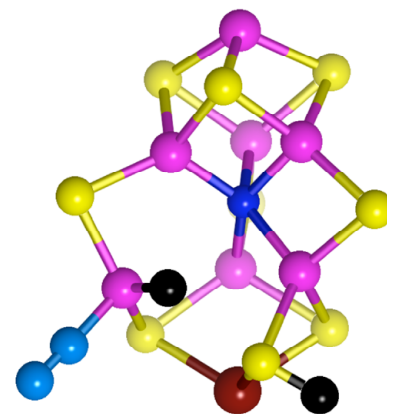

3-2H-g

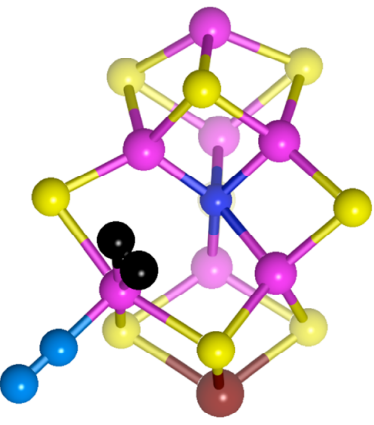

3- $\left(\mathrm{H}_{2}\right)-\mathbf{a}$

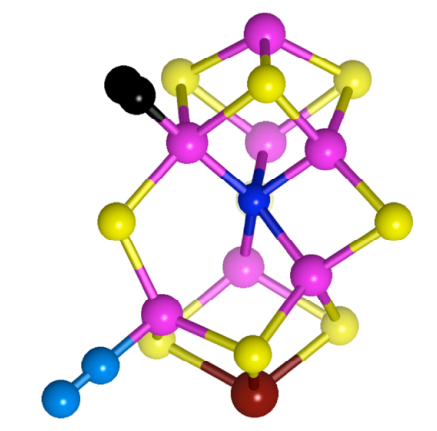

3- $\left(\mathrm{H}_{2}\right)-\mathbf{b}$

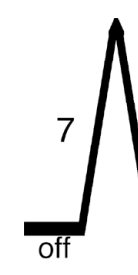

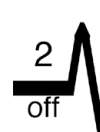

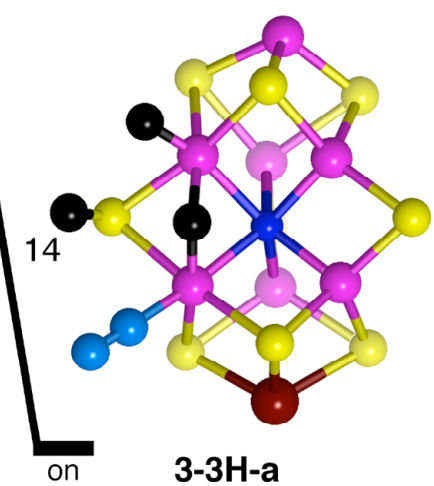

3-3H-a
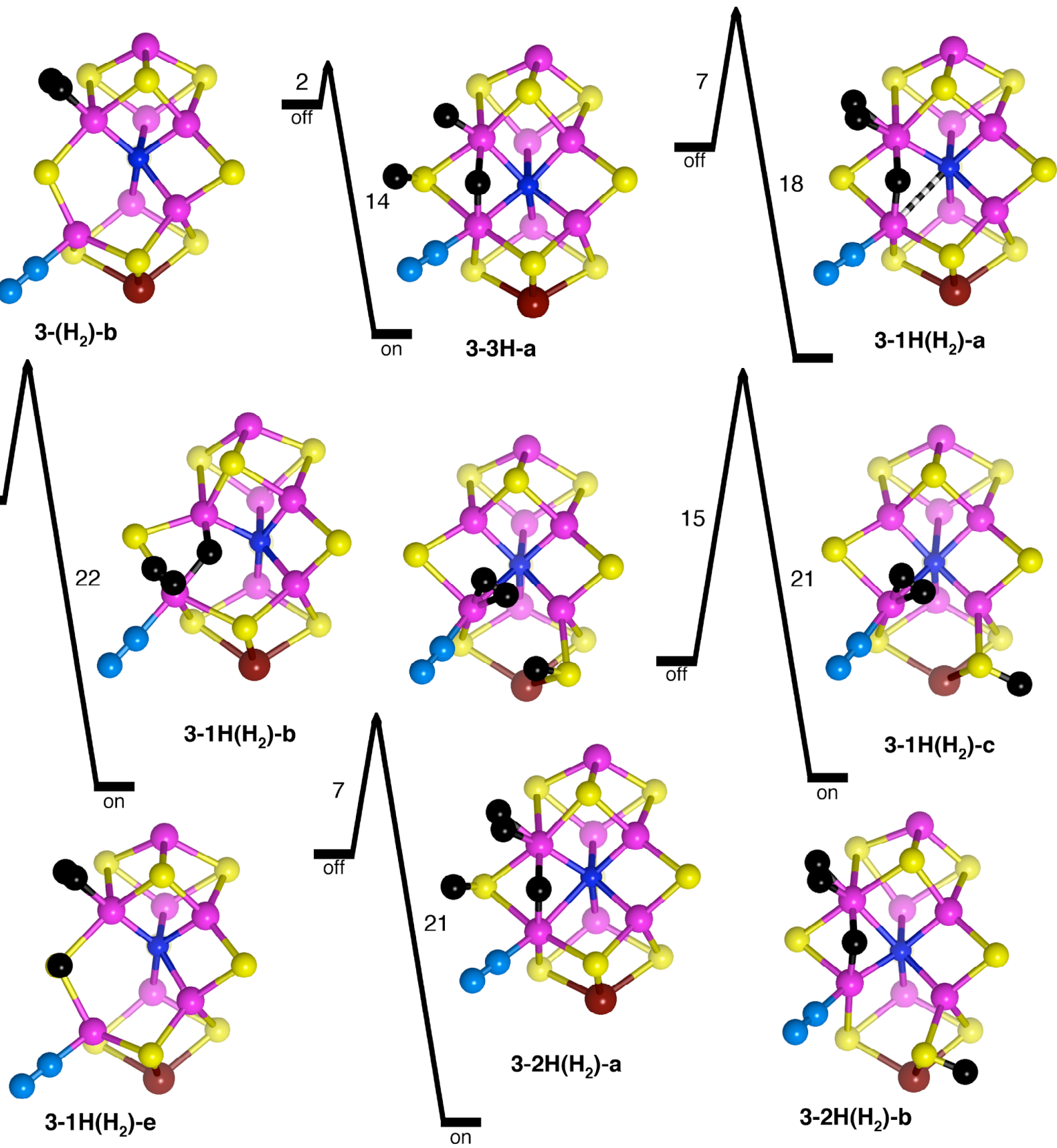

3-2H( $\left.\mathrm{H}_{2}\right)-\mathrm{b}$

Fig S3. The complete set of calculated structures and reaction profiles for $\eta^{1}-\mathrm{N}_{2}$ coordinated at the exo position of Fe6 or Fe2 in hydrogenated FeMo-co. 